Camille Venturelli Pic *

\title{
A prática da equoterapia e da educação em arte como experiência de ensino em tempos de pandemia
}

Camille Venturelli Pic é licenciada em Pedagogia pelo Centro Universitário Claretiano (2021), Mestre em Artes pela Universidade de Brasília (2019), onde realizou a sua pesquisa com bolsa de estudos (capes), aprovada pelo comitê de ética de pesquisa com seres humanos: Arte_Equoterapia: confluências na educação em artes visuais com crianças autistas. Bacharel em comunicação social - Publicidade e Propaganda pelo Centro Universitário de Brasília-IESB (2014). Participa do grupo de pesquisa Metodologias, Educação e Materiais em Artes Visuais, coordenado pela professora Dra. Thérèse Hofmann Gatti Rodrigues da Costa da Universidade de Brasília. venturellicamille@gmail.com ORCID 0000-0002-9788-0467
Resumo Este trabalho apresenta o espaço da Equoterapia em conjunto com as atividades baseadas na Educação em Artes Visuais e tecnologia, como meios para auxiliar no processo de aprendizagem de crianças com o Transtorno do Espectro Autista - TEA, em tempos de pandemia. A prática da Equoterapia e da Educação em Arte como experiência de ensino envolve também a apresentação de objetos de aprendizagem, que foram desenvolvidos durante o curso de mestrado na Universidade de Brasília, com autorização da Comissão de Ética da Universidade de Brasília. Este artigo apresenta a pesquisa realizada no mestrado e seu desenvolvimento posterior durante a pandemia, no qual amplia as referências oriundas da educação, no desenvolvimento de práticas arte-educativas e objetos de aprendizagem de Equoterapia, que auxiliem pessoas especiais.

Palavras Chave Equoterapia, TEA, Artes Visuais, Pandemia. 


\section{The practice of hippotherapy and art education as a teaching experience in times of pandemic}

Abstract This work presents the space of Hippotherapy together with activities based on Education in Visual Arts and technology, as a means to assist in the learning process of children with Autistic Spectrum Disorder - ASD, in times of pandemic. The practice of Hippotherapy and Art Education as a teaching experience also involves the presentation of learning objects, which were developed during the Master's course at the University of Brasilia, with authorization from the Ethics Committee of the University of Brasilia. This article presents the research carried out in the master's program and its subsequent development during the pandemic, in which it expands the references from education, in the development of art-educational practices and learning objects of Hippotherapy, which help special people.

Keywords Hippotherapy, ASD, Visual Arts, Pandemic.

La práctica de la hipoterapia y la educación artística como experiencia docente en tiempos de pandemia

Resumen Este trabajo presenta el espacio de la Equinoterapia junto con actividades basadas en la Educación en Artes Visuales y tecnología, como un medio para ayudar en el proceso de aprendizaje de los niños con Trastorno del Espectro Autista - TEA, en tiempos de pandemia. La práctica de la Equinoterapia y la Educación Artística como experiencia docente también involucra la presentación de objetos de aprendizaje, los cuales fueron desarrollados durante el curso de Maestría en la Universidad de Brasilia, con autorización del Comité de Ética de la Universidad de Brasília. Este artículo presenta la investigación realizada en el programa de maestría y su posterior desarrollo durante la pandemia, en la que amplía las referencias desde la educación, en el desarrollo de prácticas arte-educativas y objetos de aprendizaje de la Equinoterapia, que ayudan a personas especiales.

Palabras clave Equinoterapia, TEA, Artes Visuales, Pandemia 4. 


\section{Introdução}

Primeiramente, o artigo apresenta a origem da pesquisa realizada no curso de Pós-Graduação, nível Mestrado do Departamento de Artes Visuais da Universidade de Brasília, com a dissertação intitulada Arte_Equoterapia confluências na Educação em Artes Visuais com Crianças Autistas. A pesquisa foi defendida e aprovada no ano de 2019 e, para a sua realização, foi necessária a autorização do comitê de ética de pesquisa com seres humanos da universidade. No período de um ano ocorreram 30 sessões de Equoterapia, com 6 crianças diagnosticadas com o Transtorno do Espectro Autista - TEA. Os dias de atendimentos semanais (exceto em feriados, faltas por motivos pessoais e férias escolares), foram estipulados com a equipe da Associação Nacional de Equoterapia - ANDE-BRASIL. Para realizar a pesquisa ocorreu a mediação, de pesquisadores responsáveis pelas sessões e apoio, e com professores efetivos da secretaria de educação do Distrito Federal, que são encaminhados para trabalharem com a Equoterapia em Brasília, dando suporte às necessidades educacionais e ao desenvolvimento biopsicossocial dos deficientes.

Durante os encontros, aplicamos exercícios próprios da Equoterapia e da Equitação, com cunho pedagógico e lúdico, propostos e protocolados pela pesquisa. Os exercícios foram organizados e adaptados para cada criança, pois elas apresentavam percepções e maneiras de interagir diferente com cavalo.

Inicialmente, observávamos os aspectos da interação com o cavalo, com a equipe, com o ambiente, com o cuidar, com o brincar, com o aprender, com o fazer e com o expressar, e para isso utilizou-se elementos das linguagens artísticas e materiais das artes.

A pesquisa teve como referências os documentos do Ministério da Educação, que tratam sobre as Política da Educação Especial e Inclusiva (MEC 2008; MEC 2014), e autores como Lev Vygotsky (2001; 2010), que reflete sobre o desenvolvimento natural da criança e o percurso da aprendizagem; Paulo Freire (1967), que analisa e contribui com as práticas dos educadores, inclusive em períodos complicados na história do Brasil e da educação brasileira, como nos tempos de ditatura militar, demonstrando que a pedagogia deve sempre ser revista e estará sempre em desenvolvimento e Fernando Hernández-Hernández (2013), com a abordagem de arte/ educação, que demonstra a importância do ensino da arte, e as diversas faces que as pesquisas e investigações baseadas em arte podem apresentar, demonstrando a seriedade e a necessidade deste tipo de estudo. Fernando Hernández-Hernández, destaca como fundamental para o campo a identificação na produção cultural humana, construída na história e na contemporaneidade, do valor e das diferenças das culturas visuais, como por exemplo, as que são exibidas nas propagandas, nas obras de arte, nas arquiteturas, no design e na tecnologia de material de encilhamento de cavalos etc.

Outros autores, que subsidiaram a proposta, são especialistas em autismo como Temple Grandim (2018), que trata sobre o autismo do ponto 
de vista da pesquisadora doutora e autista. Grandim diz que a genética do autista é complexa e envolve diversas pequenas variações no código genético que controlam o desenvolvimento cerebral.

Considerando as leituras e as experiências vivenciadas antes e durante o mestrado, buscou-se potencializar por meio da união de diversas áreas de conhecimento e de vivência, o caráter positivo das atividades para o tratamento do autismo. Algumas das atividades, eram realizadas ao mesmo tempo com os cavalos e outras posteriormente.

Os resultados foram observados a partir das anotações diárias sobre as realizações de cada criança, fotografias, vídeos e, considerou as observações apresentadas pelos responsáveis dos participantes que preencheram uma avaliação no início da pesquisa, e outra no final. Este tipo de avaliação é denominado de Autism Treatment Evaluation Checlist - ATEC , e pontua o desenvolvimento global do entrevistado sobre algumas categorias das suas vidas, para compararmos a evolução positiva ou negativa em relação aos principais desempenhos da trajetória e terapias, durante um certo período de tempo. Outro resultado, que foi observado, considerou a utilização de brinquedos e objetos de aprendizagem, a partir das experiências envolvendo o ensino da arte e da equoterapia, que foram desenvolvidos especialmente para a pesquisa.

\section{Desenvolvimento da pesquisa na pandemia}

Durante a pandemia buscou-se propor um olhar sobre as reflexões de educadores que abordam princípios importantes da educação especial e que possam ser relacionadas com a Equoterapia, objetos de aprendizagem e tecnologia. A metodologia adotada foi a de revisão bibliográfica, que transita entre a pesquisa exploratória e a descritiva. Foram selecionados os autores que consideram os processos da individualidade dos educandos; de aprender brincando; do desenvolvimento sensorial; do processo de autonomia; das necessidades educativas especiais e da Equoterapia no desenvolvimento das crianças, principalmente as especiais. Também se avaliou a contribuição do uso de recursos materiais pedagógicos e de objetos de aprendizagem no desenvolvimento das crianças durante a Equoterapia.

Para justificar as escolhas em relação as referências e as metodologias, destacam-se reflexões de educadores, principalmente da autora Maria Montessori $(2010 ; 2017 ; 2019)$ e de Paulo Freire $(1967 ; 1996)$. Os autores citados levam em consideração a individualidades dos educandos e do sistema educacional, como nos aspectos sociais e culturais.

Maria Montessori (2017) diz que devemos promover para as crianças, todas as possibilidades de viverem a sua infância em plenitude, desenvolvendo as suas potencialidades. A educadora e médica Italiana, pensou sobre as relações dos pais, dos cuidadores e dos educadores com a educação e o desenvolvimento das crianças, que não deveriam ser tratadas com infe- 
rioridade por estarem em processo de crescimento. $\mathrm{O}$ ideal, para a autora, é permitir que as crianças, tenham acesso ao mundo, e aos processos de autonomia, assim como, que se expressem e que façam, naturalmente, a leitura do mundo a partir da sua perspectiva. Nesse sentido, devemos tratar as crianças com respeito, dando-lhes um espaço seguro e apropriado para aprenderem, em um curso mais natural, explorando o campo sensorial e permitindo-lhes acesso há ferramentas, para que possam se desenvolver (MONTESSORI, 2010).

A educadora também observa que o ato de brincar das crianças é muito mais do que apenas um momento de distração. Para Maria Montessori (2019), o ato de brincar é aprender. A brincadeira, é uma maneira de inspirar e expirar os sentimentos, as informações, de se movimentar, de experimentar e de sentir. Aprender brincando vai demonstrar como a criança ressignifica a sua vida e a sua rotina, explorando bem os sentidos e fazendo as devidas conexões. O brincar das crianças, nas escolas de Montessori, comprova que em um ambiente seguro e com objetos adequados e manipuláveis para as faixas etárias dos educandos, realizavam suas atividades com amor e exatidão (MONTESSORI, 2010), pois as crianças apesar de jovens, são muito criativas e são grandes descobridoras.

Considerando a autora, buscou-se na atual pesquisa durante a pandemia, incluir a brincadeira, em conjunto com a arte, a tecnologia, o aprendizado com a Equoterapia. Esta pesquisa possibilita, ao se propor recorrer ao uso do cavalo como instrumento terapêutico, dependendo da necessidade da criança, acessar o seu campo da imaginação através das brincadeiras, despertando seu interesse por meio de recursos lúdicos e pedagógicos relacionados ao próprio cavalo, aos games, aos brinquedos de casa, às terapias, ou à escola. Alguns dos recursos, usados são materiais que têm finalidade pedagógica ou de acalento como por exemplo: bolas, bichos de pelúcias, livros, brinquedos de animais, carrinhos, brinquedos educativos, entre outros. Poderíamos então começar a permitir que a criança explore todo o seu potencial de aprender mais de através do brincar na Equoterapia? Seria um avanço na busca da autonomia?

Para Vanessa Rubim (2012), terapeutas podem, e professores devem ser provocadores de pensamento. Sua pesquisa relaciona a Equoterapia e a escola. Visa analisar, como os dois campos podem auxiliar e se conectar para um melhor processo de aprendizagem e da subjetividade no pensar do sujeito, que no caso era uma pessoa com Síndrome de Down, com necessidades educacionais especiais. Rubim (2012) escreveu que quando houveram trocas de informações sobre as necessidades e as dificuldades nas atividades escolares, e que quando essas necessidades eram trabalhadas na Equoterapia, ocorreram melhoras no processo de aprendizagem escolar, principalmente em relação a subjetividade e a capacidade de o sujeito refletir. $O$ sujeito da pesquisa, também sempre trazia memórias do seu tempo com o cavalo para a as aulas na escola. Nesse caso, as observações da pesquisadora mostraram a importância de olhar para as pessoas levando em consideração que todas são únicas. 
Freire (1996), quando se posiciona sobre o valor do indivíduo, demonstra com a que as pessoas não podem ser apenas um elemento neutro na história, exemplificando que o papel do professor é ir e permitir que os alunos cheguem a lugares inalcançáveis. De acordo com o educador, as principais ferramentas que podemos usar para transcender nosso lugar na sociedade serão a capacidade de pensar, de refletir, de discutir e de saber agir, para então, poder mudar alguma coisa e contribuir.

Sobre a individualidade, é percebido no mundo todo, que muitas pessoas têm necessidades educativas especiais. Para María Royo e Natividad Urquízar (2010), a educação especial será definida como o atendimento especial e especializado para alunos que a partir de alguma deficiência tenham dificuldades ou impedimento de aprender sincronizado com os outros alunos. Desta maneira, esclarecem sobre alunos com necessidades educativas especiais:

“[...]Não só aqueles que apresentam determinadas limitações na aprendizagem, de natureza mais ou menos estável, mas também todos aqueles que, de forma pontual e por diferentes causas, possam necessitar de ajuda para dirigir ou encaminhar naturalmente seu processo de aprendizagem" (ROYO; URQUÍZAR, 2010, p. 14).

Maria Montessori reflete, em suas práticas, como as crianças com necessidades especiais irão utilizar os objetos propostos por ela. De uma maneira geral, percebe que as crianças com condições neurológicas atrasadas não farão o uso correto dos objetos montessorianos e nem terão tanto interesse inicial como uma criança dita "normal". o mediador da atividade deverá então primeiro buscar com que essa criança especial, procure aos poucos o interesse e comece a caminhar para um processo mais autônomo:

\footnotetext{
"A criança com necessidades especiais é ajudada, pelo contrário, a "compreender" o material, graças à lição; sua atenção é atraída com insistência sobre os diferentes contrastes e ele acaba por interessar-se e começa a trabalhar. Contudo, o objeto em si mesmo será um estímulo insuficiente para despertar sua atividade" (MONTESSORI, 2017, p.188)
}

No Brasil, uma maneira de auxiliar as necessidades educacionais é pela Equoterapia. No nosso país, normalmente as pessoas fazem a terapia uma vez por semana, durante 30 minutos. Nesta pesquisa, procura-se demonstrar que se forem feitas mais sessões de Equoterapia durante a semana, tendo planejamento para dias de atividades de equitação, de desenvolvimento físico/motor, de desenvolvimento emocional, sensorial e de aprendizagem, o processo de desenvolvimento global das crianças, principalmente as especiais, é mais potencializado. Quando montamos a cavalo, nosso corpo se aquece, nos acalmamos, sensações acontecem, nos sentimos mais altos, confrontados no início e depois felizes de estar e guiar um ani- 
mal maior que nós. A cavalo, podemos investigar caminhos, correr muito mais rápido que normalmente poderíamos escutar os pássaros, saltar obstáculos e finalmente ter mais liberdade.

$\mathrm{Na}$ Equoterapia, assim como nas escolas Montessori o movimento do corpo acontece durante as atividades, assim como a ativação dos sentidos também. Os materiais usados, tanto no método Montessori quanto no método da Equoterapia, costumam ser sensoriais. Mas não é só o uso dos materiais que contribuem com o processo. É necessário que as crianças passem a refletir durante o uso dos materiais e na realização das atividades, na busca da autonomia. Paulo Freire (1996) esclarece que professores devem respeitar o processo de autonomia dos educandos, pois deve-se ter cuidado nos processos de crítica, de observação e de escuta.

A utilização de brinquedos pedagógicos e objetos de aprendizagem, mostrou as muitas possibilidades para reconhecer o aprendizado das crianças com os cavalos, permitindo também que identificássemos outras maneiras das crianças se comunicarem, de ocorrer a interação social e de se expressarem pela arte. Objetos de aprendizagem podem se caracterizados por serem ferramentas para se aprender, permitindo também trabalhar a criatividade. Para Gisele Barbosa (2014) serão recursos pedagógicos que colocarão o educando para refletir. Esses recursos podem ser digitais ou não digitais.

Para Tatiana Fernández (2017), sobre o pensar artístico, existem os Objetos de Aprendizagem Poéticos, que tem como objetivo "reinventar e reconstruir conhecimento que continua a se transformar" e que trarão experiências estéticas e pedagógicas.

Sobre esses aspectos, na pesquisa que transcorreu no mestrado, foram desenvolvidos e apresentados os seguintes objetos de aprendizagem: 1. Pregadores de Encilhamento, que foi caracterizado com um Objeto de Aprendizagem Poético; 2. Pé de Pano, também como Objeto de Aprendizagem Poético; 3. Espectro do Corpo Colorido, Objeto de Aprendizagem Tecnológico Artístico (termo pensado na pesquisa), pois usou-se de referências da tecnologia, da arte e da aprendizagem. Com cada um deles, a interação das crianças foi subjetiva de acordo com a sua potencialidade. A seguir, são apresentadas imagens e algumas informações (PIC, 2019) sobre os objetos de aprendizagem desenvolvidos na pesquisa de mestrado Arte_Equoterapia:

\section{Pregadores de encilhamento}

O Objeto de Aprendizagem Poético (Figura 1) é utilizado de maneira lúdica sobre o aprendizado das características dos materiais de encilhamento básico dos cavalos (sela, manta, rédeas, cabeçada). Neste caso, pode-se trabalhar, ainda, assimilação de informações, memória, representação de tipos de imagem, cores e desenvolver aspectos físicos e psicológicos, como a coordenação motora grossa e fina, concentração, entre outros. 
Figura 1 Pregadores de encilhamento, Objeto de Aprendizagem Poético feito com pregadores de roupa, barbante e imagens impressas plastificadas Fonte Arquivo do autor, 2019

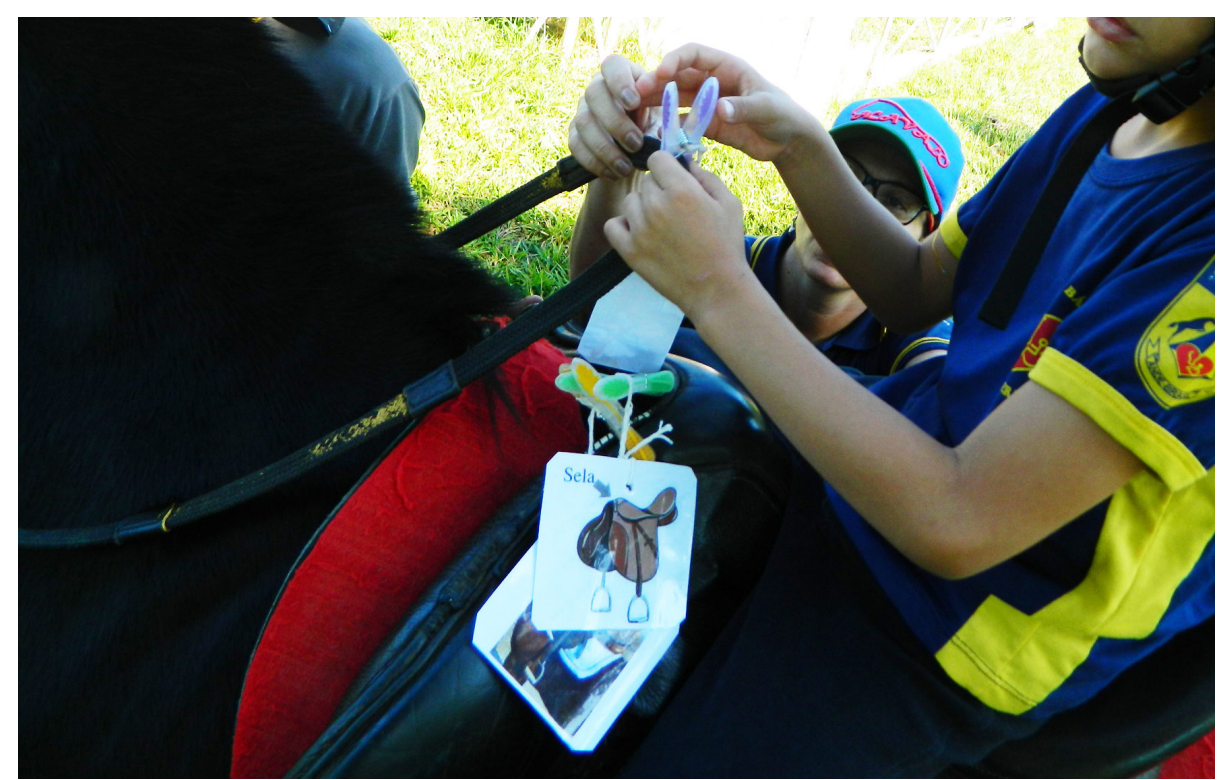

\section{Objeto de aprendizagem poético Pé de Pano}

O objeto de Aprendizagem Poético Pé de Pano (Figura 2) possibilitou trabalhar a criatividade e também a assimilação sobre algumas partes do corpo do cavalo durante a sessão de Equoterapia. Em solo, por etapas, pedimos ao praticante para colocar as partes (crina, cola e cascos) no pé de pano, mostrando as duas opções de cores e permitindo que ele faça a sua escolha. Sobre as outras partes do cavalo, como garupa, pescoço, barriga, patas, o praticante pode falar, apontar ou acariciar.

Figura 2 Pé de Pano, Objeto de Aprendizagem Poético foi desenvolvido com tecido, algodão, botões, velcro e TNT Fonte Arquivo do autor, 2019

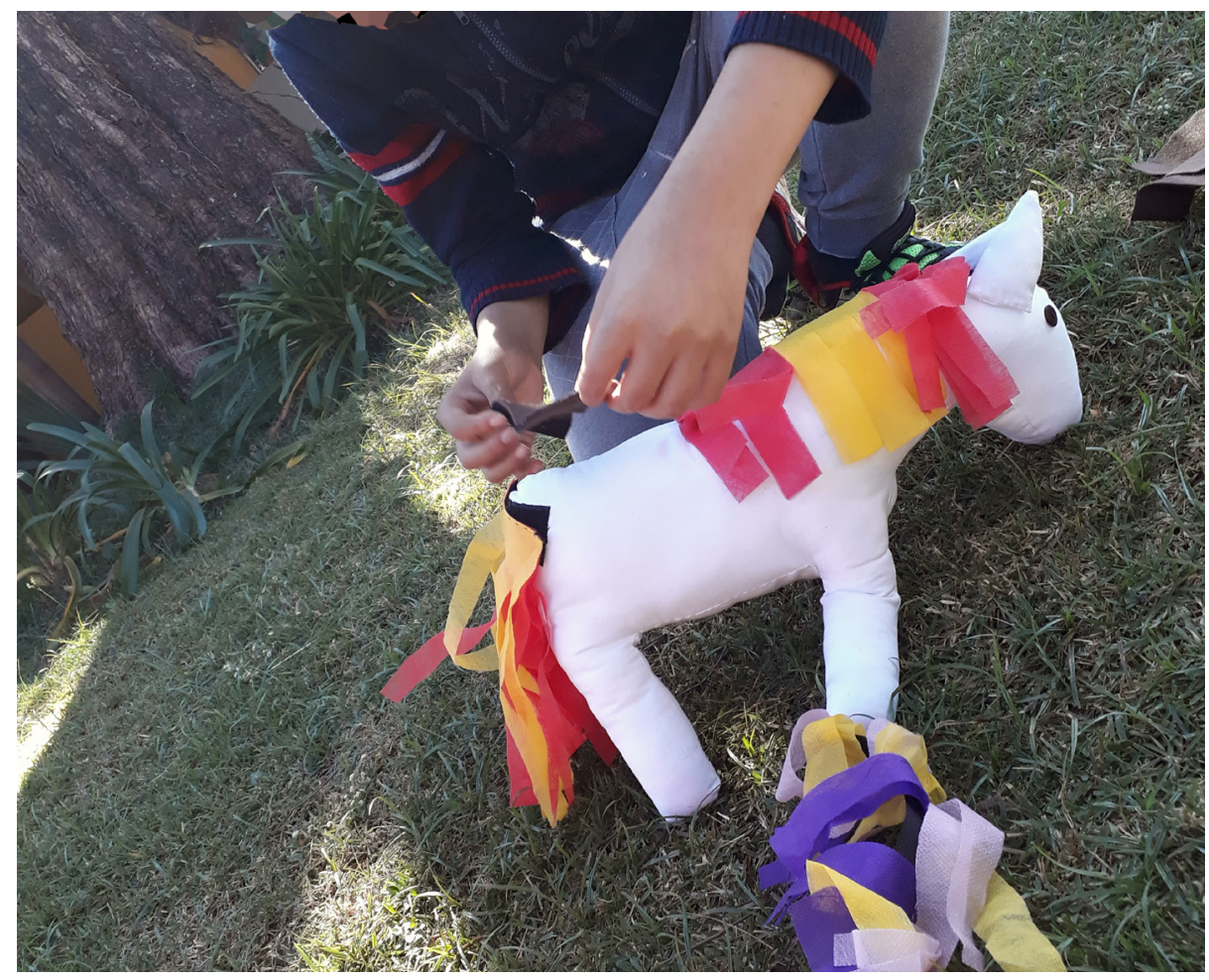




\section{Objeto aprendizagem tecnológico artístico (OATA) espectro do corpo colorido}

O Objeto de Aprendizagem Tecnológico Artístico (OATA) Espectro do Corpo Colorido (Figura 3), teve como característica o uso de tecnologia contemporânea através do uso do computador, dispositivo Kinnect, projetor, o software processing 2.1 e tecnologias naturais como o picadeiro coberto do local da pesquisa, a energia, areias, pessoas e cavalos. Com o uso do Espectro do Corpo Colorido, foram feitas sessões interativas com arte, pois nos aproximávamos e nos distanciávamos com os conjuntos de cavalos e praticantes do dispositivo Kinnect, e assim que os corpos em movimento ou parados eram percebidos pelos dispositivos e projetava-se imagens com cores mais quentes (para perto) ou cores mais frias (para longe). As imagens digitalizadas eram projetadas espelhadas com sombreado e traçado colorido dos corpos, em um telão. Esse tipo de efeito foi programado em um software com algoritmo de visão computacional 3D, que é capaz de identificar objetos e o espaço. Nestas sessões, pode-se trabalhar questões de espacialidade, cores, percepção corporal, desenvolvimento sensório-motor, condução do cavalo, entre outros.

Figura 3 Espectro do Corpo Colorido, objeto de Aprendizagem Tecnológico Artístico

Fonte Arquivo do autor, 2019

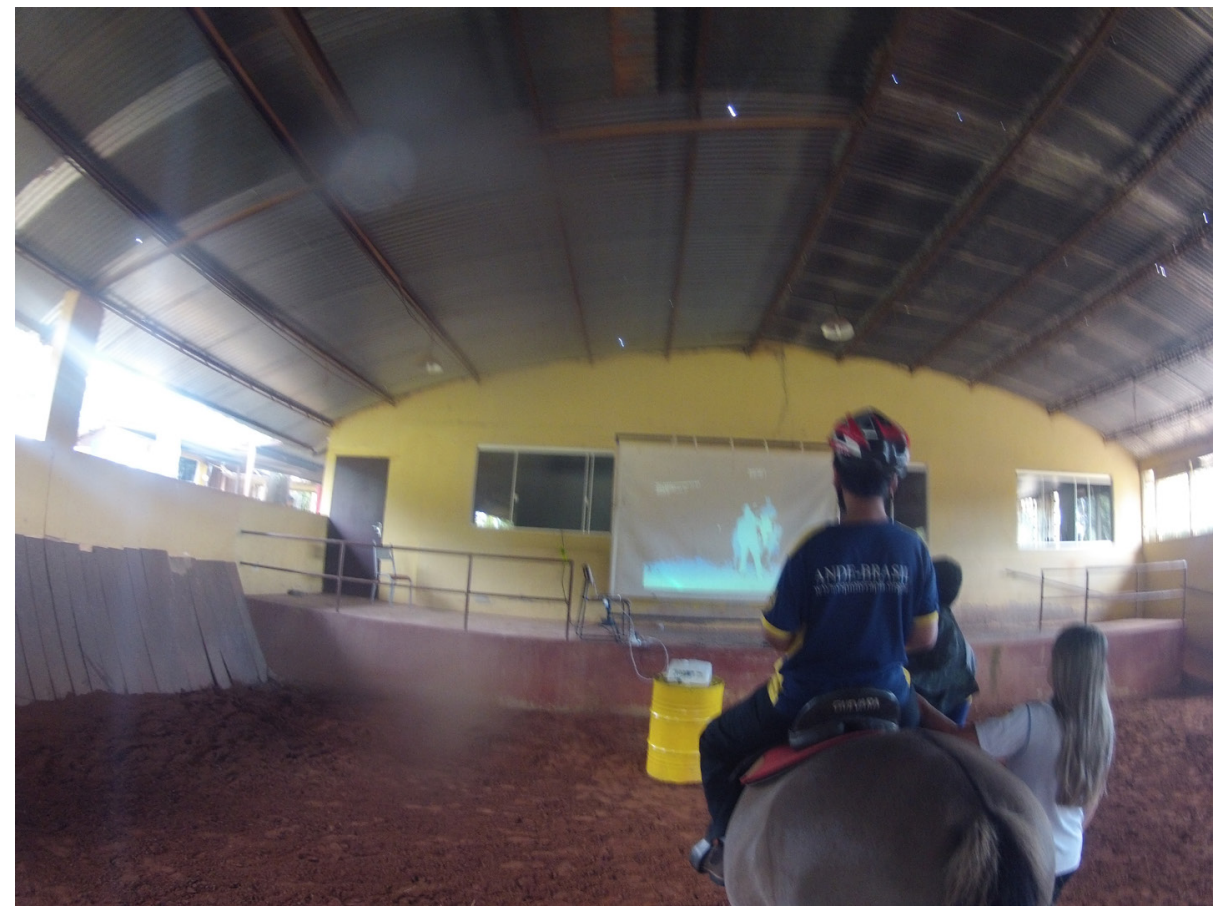

Os objetos de design, citados a cima, ainda são recursos ineridos no dia-a-dia de sessões de Arte_Equoterapia pela pesquisadora. Durante a pandemia, em Brasília, os responsáveis de pessoas com deficiência continuaram a procurar o tratamento com a Equoterapia e para auxiliá-los no aprendizado foram pensados materiais pedagógicos e objetos de aprendizagem que pudessem ser utilizados, posteriormente em casa. Nesse viés, o 
Figura 4 Captura de tela das páginas do aplicativo Meu Cavalo Bonitinho. Disponível em https://app.vc/meu_cavalo_bonitinho_2503730

Fonte Arquivo do autor, 2020 protótipo de um aplicativo informativo, denominado Meu Cavalo Bonitinho (Figura 4), que mesmo em desenvolvimento, foi desenvolvido e utilizado pelos praticantes. Neste aplicativo para celular, existem algumas informações e imagens de dois cavalos que participam das sessões de Equoterapia no Centro Hípico Pietra César. De acordo com os responsáveis dos praticantes, houve muito interesse em continuar desenvolvendo a aprendizagem, em casa, com o aplicativo para celular.

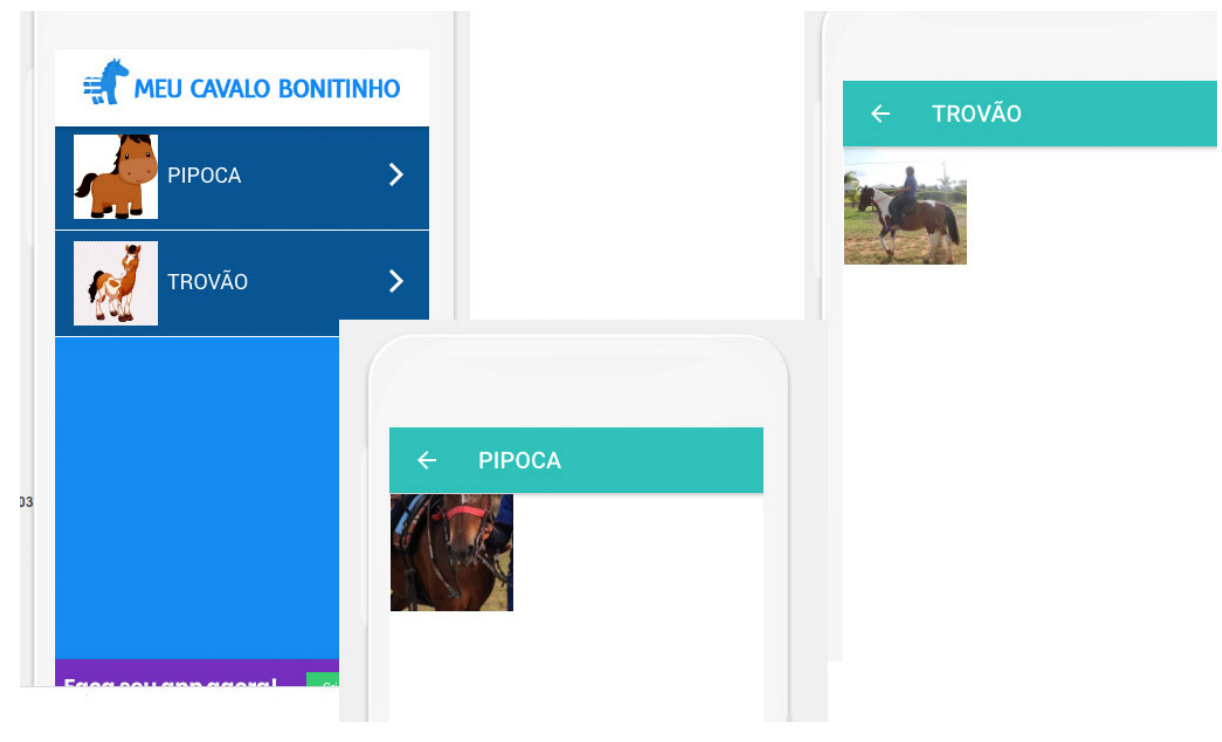

\section{Conclusão}

Existem possibilidades de serem acrescentadas no desenvolvimento da criança no contexto da Equoterapia como recursos pedagógicos, artísticos, tecnológicos adaptados para os aspectos lúdicos do ato de brincar aprendendo. Esses recursos motivadores para as crianças especiais, pois possibilitam que elas descubram sobre o mundo a sua volta, com ajuda do cavalo, espécie de vida essencialmente livre.

Apesar de Maria Montessori e Paulo Freire serem de culturas diferentes, ambos pensaram em processos para desenvolver a autonomia dos educandos e costumam perceber as práticas que colaboram para a sua independência, como um critério fundamental. Nesse caso, o desenvolvimento sensorial e do movimento do corpo, ajudam as crianças a se desenvolverem globalmente.

Considerando o que foi desenvolvido até o momento, pretende-se para o futuro da pesquisa, que a metodologia seja aperfeiçoada a partir dos resultados apresentados, assim como, pretende-se criar novos objetos de aprendizagem, poéticos tecnológicos, conceituados a partir da própria área da pedagogia, cujos pensamentos proporcionam apropriados caminhos educativos no contexto especiais dos praticantes. Ou seja, como aponta Montessori é fundamental para as crianças executar as atividades com mais autonomia para que possam criar novas conexões cerebrais e terem ganhos 
físicos. Além disso é necessário conduzi-las a explorarem as brincadeiras e os objetos para que possam passar a refletir mais sobre o que estão fazendo.

Nesse caminho, que une reflexões sobre o brincar, sobre a importância do espaço da escola, do papel do professor, das potências da Equoterapia, da importância da subjetividade da brincadeira, do aprendizado da criança e do desenvolvimento da criatividade, para que se possa alcançar o lugar do pensar e refletir, que a pesquisa caminha. Brincar na Equoterapia com elementos que tenham características de aprendizagem, os professores e os terapeutas, em comunhão, poderão permitir que haja o lugar do aprender, do refletir e do modificar a partir da subjetividade da brincadeira de cada criança.

Considerando as reflexões apresentadas, conclui-se que o praticante de Equoterapia poderá, a partir dos métodos, se tornar um participante ativo ou mais energizado, no seu processo de aprendizagem. Nesse sentido, pode-se afirmar que o espaço da Equoterapia é um local eficaz para que às crianças especiais possam adquirir conhecimento e bem-estar, principalmente durante crises. Além de práticas para a aprendizagem, quando se relaciona Educação, Arte, Tecnologia e Equoterapia dialoga-se com o desenvolvimento das habilidades motoras, do desenvolvimento da linguagem, do desenvolvimento sensorial, do emocional e do social, utilizando-se de muita criatividade. 


\section{Referências}

ANDE-BRASIL - Disponível em https://www.equoterapia.org.br. Acesso 15 set. 2020.

ATEC - Disponível em https://www.autism.org/autism-treatment-evaluation-checklist. Acesso 20 ago. 2020.

BARBOSA, Gisele. Manual do professor para utilização de objetos de aprendizagem. UFJF, MG. 2014.

FERNANDES, Tatiana e DIAS, Belidson. Objetos de aprendizagem poéticos: máquinas para construir territórios de subjetivação. Disponível em: http://anpap.org.br/anais/2015/ simposios/s8/tatiana_fernandez_belidson_dia s.pdf. Acesso 1 dez. 2017.

CAMPOS, J. (org.). Psicologia da educação. Batatais,SP : Claretiano, 2013. 234 p.

CEZAR, A.T. Gestaltpedagogia: Um caminho trilhado na intersubjetividade. Debates em Educação. Vol. 10 - No 20. Rio de Janeiro, 2018.

CORREA, R.A; KRASTANOV, S.V. Fundamentos históricos e filosóficos da educação. Batatais - SP: Claretiano, 2013. $198 \mathrm{p}$.

DUARTE, N. Vigotski e o "aprender a aprender": crítica às apropriações neoliberais e pós-modernas da teoria vigotskiana. Campinas, SP: Autores Associados, 2001.

FREIRE, P. Educação como prática da liberdade. Editora Paz e Terra. Brasil, 1967. Disponível em http://www.gestaoescolar.diaadia.pr.gov.br/arquivos/File/otp/livros/educacao_ pratica_liberdade.pdf Acesso 04 set. 2020.

FREIRE, P. Pedagogia da autonomia: saberes necessários à prática educativa. São Paulo: Editora Paz e Terra, 1996.

GRANDIM, T. Is Autism the Price for a Human Brain? Dept. of Animal Science - Colorado State University. 2018, USA. Disponível em http://www.templegrandin.com/temple_articles. Acesso 12 set. 2020.

HÉRNANDEZ, F. H. in DIAS, B.; IRWIN, R. (orgs.). Pesquisa Educacional Baseada em Arte: A/R/Tografia. Santa Maria: Editora UFSM, 2013.

Instituto Maria Montessori. Disponível em https://www.mariamontessori.org/our-community/useful-articles. Acesso 05 ago. 2020.

Ministério da Educação. Política Nacional da Educação Especial na Perspectiva da Educação Inclusiva. MEC, 2008. Disponível em http://portal.mec.gov.br/arquivos/pdf/politicaeducespecial.pdf. Acesso em: 10 set. 2020.

Ministério da Educação. Política Nacional de Educação Especial na Perspectiva da Educação Inclusiva. MEC, 2014. Disponível em: http://portal.mec.gov.br/index. php?option=com_docman\&view=download\&alias=16690-politica-nacional-de-educacao-especial-na-perspectiva-da-educacao-inclusiva-05122014\&Itemid=30192. Acesso 10 set. 2020.

MONTESSORI, M. A descoberta da criança: pedagogia científica. Campina: Kírion, 2017. MONTESSORI, M. o segredo da infância. Campinas: CEDET, 2019. 
PIC, C. V. Arte Equoterapia: Confluências na Educação em Artes Visuais com Crianças Autistas. Brasília - UNB, 2019. Disponível em: https://repositorio.unb.br/handle/10482/35312. Acesso 10 set. 2020.

ROHRS, H. Maria Montessori. Recife: Fundação Joaquim Nabuco - Editora Massangana, 2010 .

RUBIM, Vanessa M. Equoterapia, escola e subjetividade: promoção da saúde, aprendizagem e desenvolvimento da criança. Brasília - UNB, 2012. Disponível em: https://repositorio.unb.br/handle/10482/11093. Acesso 22 set. 2020.

SEPAHBAN, L. Temple Grandin: inspiring animal-behavior scientist. Disponível em: https://books.google.com.br/books?id=C1hFBAAAQBAJ\&printsec=frontcover\&dq=temple+grandin\&hl=pt-BR\&sa=X\&ved=2ahUKEwjOr_XwsoLsAhXCILkGHTTgDl8Q6AEwAXoECAEQA$\mathrm{g} \# \mathrm{v}=$ onepage\&q=temple\%20grandin\&f=false. Acesso 24. Set. 2020.

VIGOTSKI, L. S. Psicologia Pedagógica. São Paulo: Editora WMF Martins Fontes, 2010.

WALTER, G. B. Equoterapia - fundamentos científicos. São Paulo: Editora Atheneu, 2013.

WICKERT, H. O cavalo como instrumento cinesioterapêutico. Disponível em http://equoterapia.org.br/media/artigos-academicos/documentos/11021000.pdf. Acesso 26 ago. 2020. 